\title{
COMPARISON BETWEEN TWO TESTS OF DELAYED RECALL FOR THE DIAGNOSIS OF DEMENTIA
}

\author{
Leonel Tadao Takada', Paulo Caramelli', Helenice Charchat Fichman', \\ Cláudia Sellitto Porto', Valéria Santoro Bahia ${ }^{1}$, Renato Anghinah', \\ Maria Teresa Carthery-Goulart', Márcia Radanovic', Jerusa Smid', \\ Emílio Herrera Jr. ${ }^{2}$, Ricardo Nitrini ${ }^{1}$
}

\begin{abstract}
Diagnosis of dementia is a challenge in populations with heterogeneous educational background. Objective: To compare the accuracies of two delayed recall tests for the diagnosis of dementia in a community with high proportion of illiterates. Method: The delayed recall of a word list from the CERAD battery (DR-CERAD) was compared with the delayed recall of objects presented as line drawings from the Brief Cognitive Screening Battery (DR-BCSB) using ROC curves. Illiterate ( 23 controls and 17 patients with dementia) and literate individuals ( 28 controls and 17 patients with dementia) were evaluated in a community-dwelling Brazilian population. Results: The DR-BCSB showed higher accuracy than the DRCERAD in the illiterate $(p=0.029)$, similar accuracy in the literate individuals $(p=0.527)$, and a trend for higher accuracy in the entire population $(p=0.084)$. Conclusion: the DR-BCSB could be an alternative for the diagnosis of dementia in populations with high proportion of illiterates.
\end{abstract}

KEY WORDS: dementia, Alzheimer's disease, memory, neuropsychological tests, educational status, illiteracy.

\begin{abstract}
Comparação entre dois testes de recordação tardia para o diagnóstico de demência
RESUMO - O diagnóstico de demência é um desafio em populações com heterogeneidade educacional. Objetivo: Comparar as acurácias de dois testes de recordação tardia no diagnóstico de demência em comunidade com alta prevalência de analfabetos. Método: $O$ teste de recordação tardia de lista de palavras da bateria CERAD (RT-CERAD) foi comparado com o de re co rdação tardia de figuras simples da bateria de testes neuropsicológicos breves (RT-BTNB), utilizando-se curvas ROC. Indivíduos analfabetos (23 controles e 17 pacientes com demência) e alfabetizados (28 controles e 17 pacientes com demência) foram avaliados em uma comunidade brasileira. Resultados: O RT-BTNB demonstrou maior acurácia que a RT-CERAD entre os analfabetos $(p=0,029)$, acurácia similar nos indivíduos alfabetizados $(p=0,527)$, e tendência a maior acurácia na população inteira $(p=0,084)$. Conclusão: A RT-BTNB pode ser uma alternativa para o diagnóstico de demência em populações com alta prevalência de analfabetos.
\end{abstract}

PALAVRAS-CHAVE: demência, doença de Alzheimer, testes neuropsicológicos, analfabetismo, escolaridade.

Delayed recall tests have high accuracy for dementia diagnosis, especially for Alzheimer's disease (AD)' ${ }^{1}$. The delayed recall of a word list from the Consortium to Establish a Registry for Alzheimer's disease (CER$A D)$ neuropsychological battery (DR-CERAD) is a widely used test that has shown good correlation between specificity and sensitivity ${ }^{2}$, besides being highly accurate in the diagnosis of $A D^{3,4}$ or dementia ${ }^{5}$. In this test, the words are originally presented to the subject through a printed list, which is read aloud by the subject. However, the list must be read aloud by the examiner if the subject is illiterate or is unable to read due to visual processing disturbances ${ }^{4}$. It is probable that this distinct form of presentation determines a less favorable encoding condition for the illiterates ${ }^{6}$, making this test less sensitive for the evaluation of population with a high proportion of illiterates.

A test that can be applied equally, regardless of the subject's education, could accordingly be more adequate for a neuropsychological evaluation. Thus, the delayed recall of simple objects presented as line

\footnotetext{
${ }^{1}$ Behavioral and Cognitive Neurology Unit, Department of Neurology, Hospital das Clínicas, University of São Paulo (USP) School of Medicine, São Paulo SP, Brazil; '2Department of Internal Medicine, Catanduva School of Medicine, Catanduva SP, Brazil. This study was supported by FAPESP (Fundo de Amparo à Pesquisa do Estado de São Paulo), which also sponsored a scientific initiation scholarship for Leonel Tadao Takada.
}

Received 3 June 2005, received in final form 1 September 2005. Accepted 21 October 2005. 
drawings from the Brief Cognitive Screening Battery (DR-BCSB) ${ }^{6,7}$ could be an alternative to the DR-CER$A D$, in the diagnostic approach of dementia in population with heterogeneous educational background.

In a recently published paper ${ }^{6}$, no diffe rence in performance was found when illiterate and literate nondemented individuals were compared using the $D R-B C S B^{6}$. On the other hand, significant difference in perf o rmance was observed according to educational status (literate individuals had a significant superior performance) in the DR-CERAD ${ }^{6}$. Based on that, this study aims to compare, in the diagnosis of dementia, the accuracy of the DR-CERAD neuropsychological battery, with the accuracy of the DR-BCSB applied to a population comprising illiterate and literate individuals.

\section{METHOD}

In June, 2000, in the incidence arm of a Brazilian epidemiological study on dementia, 1119 individuals aged 68 years or more were screened in the town of Catanduva, Southeastem Brazil ${ }^{8}$. After the screening phase, a more thorough diagnostic evaluation was perf o rmed on individuals with suspected dementia (scores above five at Pfeffer Functional Activities Questionnaire [PQAQ $]^{9}$ and below specific education-adjusted scores at the Mini-Mental State Examination [MMSE] $\left.{ }^{10}\right)$. The cut-off scores employed for MMSE were higher than previously proposed ${ }^{11}$ so that screening was more sensitive (27 for subjects with more than seven years of schooling; 24 for the ones with one to seven years of schooling and 19 for illiterates). The evaluation was aimed at obtaining a cognitive profile for each subject and comprised clinical history, physical and neurological examination and neuropsychological tests [including, besides the delayed recall tests, the MMSE, verbal fluency (animals/minute), the modified Boston nam ing test and constructional praxis test from the Brazilian version of the CER$A D^{4}$; verbal fluency (fruits/minute), the clock drawing test ${ }^{12}$, the BEHAVE-AD ${ }^{13}$, and the Cornell Scale for Depression in Dementia $\left.{ }^{14}\right]$, such that a cognitive profile for each subject could be obtained. Dementia severity was rated using the clinical dementia rating scale $(C D R)^{15}$. For each case, the diagnosis of dem entia was made in a consensus meeting between nine neurologists and one psychiatrist, and was based on the DSM-IV criteria ${ }^{16}$.

The diagnosis of $A D$ was established according to the criteria from the NINCDS-ADRDA (National Institute of Neurological and Communicative Disorders and Stroke Alzheimer's Disease and Related Disorders Association) ${ }^{17}$. Vascular dementia $(\mathrm{VaD})$ or cere b rovascular disease with $A D$ diagnoses were based on the National Institute of Neurological Disorders and Stroke-Association Intemationale pour la Recherche et L'Enseigment en Neurosciences (NINDSAIREN) criteria ${ }^{18}$. McKeith et al. criteria ${ }^{19}$ was used for dementia with Lewy bodies cases. Other diagnoses were made based on usual criteria. The evaluation was supplemented by laboratory tests and brain computed tomography, so as to rule out other etiologies for dementia. In-depth description of methods have been published in recent studies $^{8,20}$.

Fifty incident cases of dementia were diagnosed, 25 being CDR 1, nine CDR 2 and 16 CDR 3. Only patients with CDR 1 or 2 were included in the present study. The patients were divided in two groups: dementia-illiterates, which was composed by 17 individuals with less than one year of school attendance, considered by themselves unable to read and unable to read "close your eyes" from the MMSE; and dementia-literates with 17 individuals with one year or more of schooling.

$A D$ was diagnosed in 21 cases (9 of which were illiterate). Among $A D$ cases, there were 5 cases diagnosed as being possible $A D$ and 4 cases of probable $A D$ in the illiterate population. Am ong literates, there were 5 cases of possible $A D$ and 7 cases of probable $A D$. Other diagnoses found were: $\operatorname{VaD}$ (6 cases), dementia associated with Parkinson's disease (3 cases), AD with cerebrovascular disease (1 case), dementia with Lewy bodies (1 case), Huntington's disease (1 case) and 1 case of undetermined etiology.

The control group $w$ as drawn from the same population evaluated in Catanduva and was composed of individuals with no history of memory deficits or who had solely mild complaints. Their results in the MMSE were above education-adjusted scores and their score in the Pfeffer Questionnaire of Functional Activities below 6 points. Furthermore, individuals with previous history of stroke or symptoms suggestive of depression (equating to score above seven in the Cornell scale for depression) were excluded from the control group, so that the final control group was composed of 51 people: 23 illiterates (contro I-ill it e r ate group) and 28 individuals with one year or more of schooling (control-literate group).

The characteristics of each group according to age, gender and schooling years are presented in Table 1. In the illiterate population, no diffe rence was found regarding gender distribution $(p=0.481)$ between the control and the dementia groups, whereas the dementia group was significantly older than the control group $(p=0.002)$. In the literate population, the dementia group was also older $(p<$ $0.001)$ and had more women $(p=0.045)$ than the control group, although no difference was seen concerning years of schooling ( $p=0.797)$.

When the two groups of patients with dementia (literate and illiterate) were compared, they did not differ according to age $(p=0.496)$ or gender $(p=1.0)$, while the two control groups differ according to gender $(p=0.004)$ but not to age $(p=0.608)$.

Regarding the severity of dementia, there were 14 cases classified as CDR 1 and three cases as CDR 2 in the dementia-illiterates group, while there were 11 cases classified as CDR 1 and 6 cases as CDR 2 in the dementia-literates group $(p=0.244)$.

For the DR-CERAD, ten separately printed words were shown to the subject, such that one new word was presented every two seconds. At the same time, the subject was asked to read each word aloud (in cases of illiteracy, the presentation was made by the examiner, who read out the 
Table 1. Means ( \pm standard deviation) regarding age, schooling years and tests' scores and gender distribution in each group.

\begin{tabular}{lcccc}
\hline & Control-illiterates & Dementia-illiterates & Control-literates & Dementia-literates \\
\hline Age & $74.04 \pm 5.00$ & $79.65 \pm 5.26$ & $73.57 \pm 5.87$ & $81.35 \pm 7.00$ \\
Gender* & $7 \mathrm{M}: 16 \mathrm{~W}$ & $7 \mathrm{M}: 10 \mathrm{~W}$ & $20 \mathrm{M}: 8 \mathrm{~W}$ & $7 \mathrm{M}: 10 \mathrm{~W}$ \\
Schooling years & 0 & 0 & $3.82 \pm 3,31$ & $3.82 \pm .322$ \\
$\begin{array}{l}\text { Delayed recall of drawings } \\
\text { from the BCSB (score) }\end{array}$ & $6.87 \pm 1.51$ & $1.60 \pm 1.84$ & $7.26 \pm 1.56$ & $2.00 \pm 2.00$ \\
$\begin{array}{l}\text { Delayed recall of a word list } \\
\text { test from the CERAD battery (score) }\end{array}$ & $3.70 \pm 2.09$ & $1.07 \pm 1.16$ & $4.96 \pm 1.34$ & $0.94 \pm 1.24$ \\
\hline
\end{tabular}

${ }^{*} \mathrm{M}$, men; $\mathrm{W}$, women.

words for the subject). The list was displayed three times, and after each presentation the subject was asked to recall as many words as possible (this being the word list memory task). Then the subject was requested to copy four geometric drawings (constructional praxis), and after this interference, the subject was requested to recall as many words of the list as he or she could, this being the delayed recall of a word list.

For the DR-BCSB, a paper sheet with ten line drawings was displayed to the subject. First, the subject was requested to name each drawing. Soon after that, the sheet was placed out of view, and the subject was asked to recall the drawings (incidental memory). The sheet was then shown to the patient again twice (for thirty seconds each time), and recall was requested after each presentation (immediate memory and learning tests). After an interfe rence constituted by a verbal fluency test (number of fruits said in one minute) and the clock drawing test the subject was asked to recall as many items as he or she could, this being the DR-BSCB score.

The accuracy of each test was obtained by the calculation of the area under the ROC (receiver operator characteristic) curve (AUC-ROC) and diffe rences between AUCROC were ascertained ${ }^{21}$. The analyses were performed comparing all dementia cases (CDR 1 or 2 ) with controls in the literate and in the illiterate groups. A separate analysis was also performed for AD cases.

The results were analyzed by means of two statistics programs: Medcalc and the Statistical Package for the Social Sciences for Windows (SPSS), version 10.0. Data in scale variables were analyzed with Mann-Whitney nonpara metric test and nominal data were compared using chi square test. It was admitted $\alpha=5 \%$ for statistically significant differences.

This study was approved by the Ethics Committee of Hospital das Clínicas, University of São Paulo School of Medicine. Every subject (or a relative, when appropriate) was informed about the study prior to the evaluation, signing thereafter an informed consent term.

\section{RESULTS}

The scores in the DR-CERAD and DR-BCSB were compared between the dementia (dementia-literate and dementia-illiterate) groups and the control (control-literate and control-illiterate, respectively) groups. In every single analysis a statistically significant difference $(p<0.001)$ in performance between the dementia and the control groups was observed, so that the control groups had higher scores in each test than the respective dementia group.

There was a statistically significant difference between the accuracy of the DR-CERAD and the accuracy of the DR-BCSB in the diagnosis of dementia among the illiterates, as the latter showed higher accuracy $(p=0.029)$. No diffe rence was found in accuracy between these two delayed recall tests when only the literate individuals were considered $(p=$ 0.527 ), while there was a trend for higher accuracy

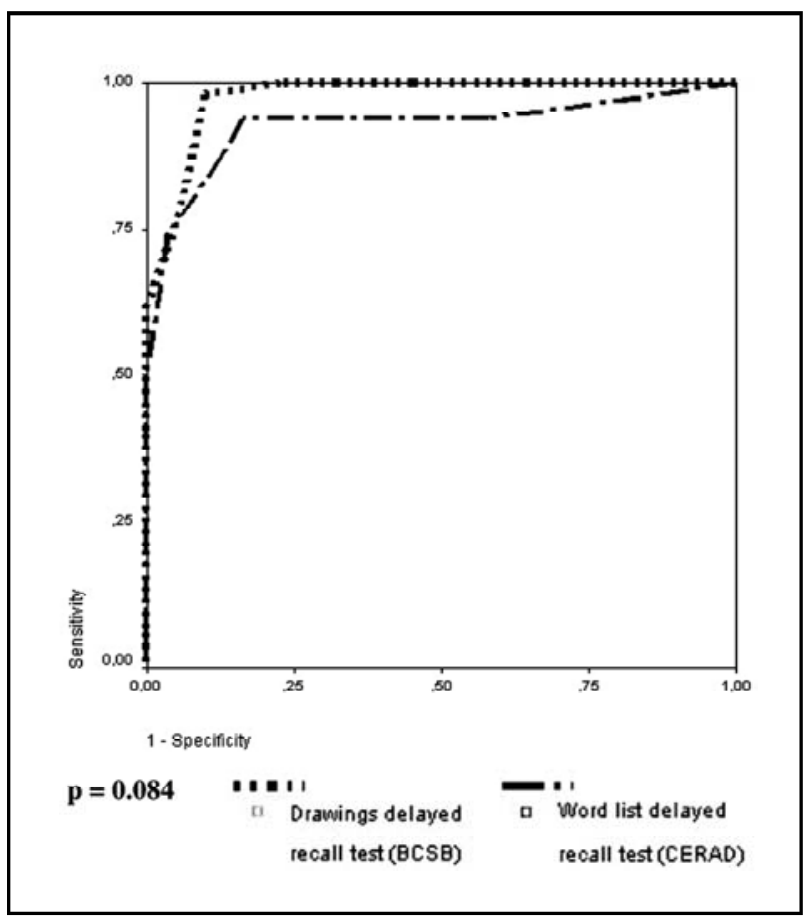

Graph 1. ROC curves for the entire population (literates and illiterates). 


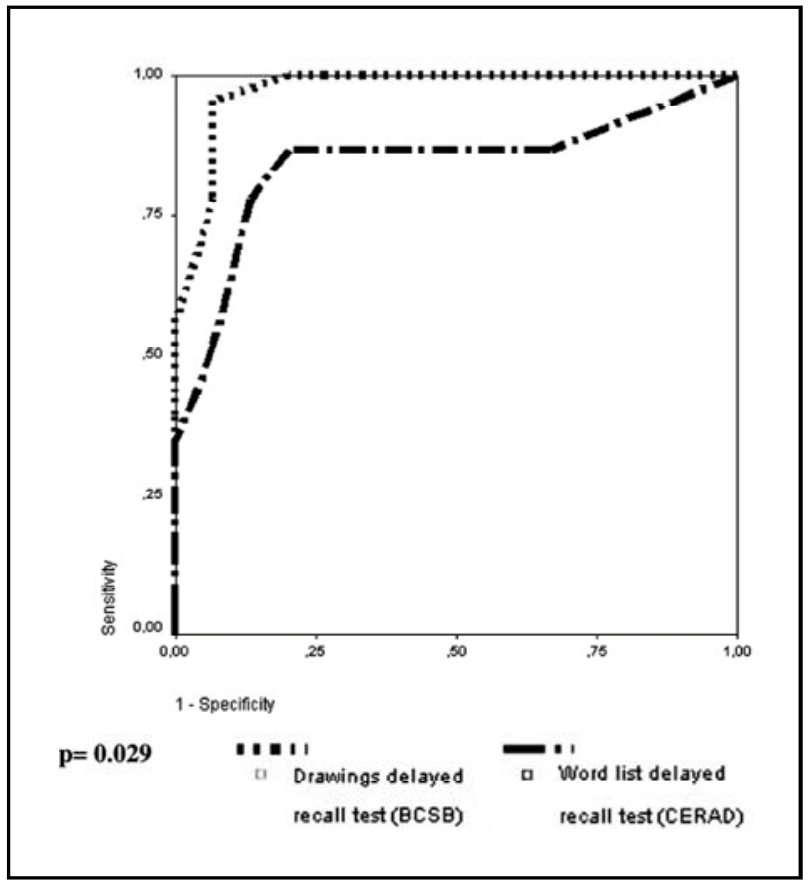

Graph 2. ROC curves for the illiterate population.

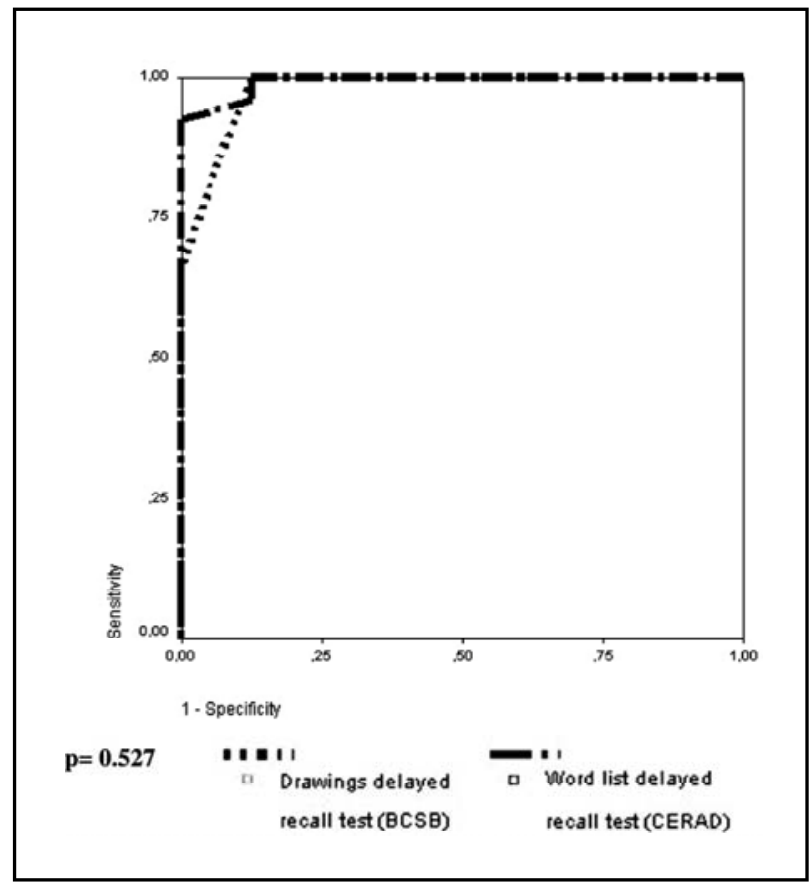

Graph 3. ROC curves for the literate population.

Table 2. AUC-ROC, 95\% confidence interval, cut-off, sensitivity and specificity for each test, considering the entire population sample.

\begin{tabular}{|c|c|c|c|c|c|}
\hline & AUC-ROC & $95 \% \mathrm{Cl}$ & Cut-off & Sensit. & Specif. \\
\hline \multicolumn{6}{|c|}{ Delayed recall of simple objects presented } \\
\hline as line drawings from the BCSB & 0.977 & $0.917-0.997$ & 4 & 90.3 & 98 \\
\hline \multicolumn{6}{|c|}{ Delayed recall of a word list test from the } \\
\hline CERAD neuropsychological battery & 0.929 & $0.849-0.974$ & 1 & 81.2 & 94.1 \\
\hline
\end{tabular}

Table 3. AUC-ROC, 95\% confidence interval, cut-off, sensitivity and specificity for each test, considering illiterates.

\begin{tabular}{|c|c|c|c|c|c|}
\hline & AUC-ROC & $95 \% \mathrm{Cl}$ & Cut-off & Sensit. & Specif. \\
\hline \multicolumn{6}{|c|}{ Delayed recall of simple objects presented } \\
\hline as line drawings from the BCSB & 0.975 & $0.864-0.995$ & 4 & 93.3 & 95.7 \\
\hline \multicolumn{6}{|c|}{ Delayed recall of a word list test from the } \\
\hline CERAD neuropsychological battery & 0.845 & $0.691-0.941$ & 1 & 80 & 87 \\
\hline
\end{tabular}

Table 4. AUC-ROC, 95\% confidence interval, cut-off, sensitivity and specificity for each test, considering literates.

\begin{tabular}{|c|c|c|c|c|c|}
\hline & AUC-ROC & $95 \% \mathrm{Cl}$ & Cut-off & Sensit. & Specif \\
\hline \multicolumn{6}{|c|}{ Delayed recall of simple objects presented } \\
\hline as line drawings from the $B C S B$ & 0.980 & $0.882-0.996$ & 4 & 87.5 & 100 \\
\hline \multicolumn{6}{|c|}{ Delayed recall of a word list test from the } \\
\hline CERAD neuropsychological battery & 0.993 & $0.904-1.000$ & 3 & 94.1 & 92.9 \\
\hline
\end{tabular}

of the DR-BCSB for the entire population $(p=0.084)$. The ROC curves and the AUC-ROC, as well as the comparison between the AUC-ROC for each test are shown in Graphs 1, 2 and 3 and Tables 2, 3 and 4.
Tables 2, 3 and 4 also include cut-off, sensitivity and specificity for each test.

$A D$ cases analysis - AD cases were also separated in two groups: the AD-illiterate group (with nine 
individuals) and the AD-literate group (with 12 individuals).

The AD-illiterates group was composed of three men and six women and had a mean age of 79.89 $( \pm 5.11)$ years. No diff e rences regarding age $(p=0.06)$ or gender distribution $(p=0.874)$ were found when the AD-illiterate and the control-illiterate groups were compared.

The AD-literate group, with five men, had mean age of $82.67( \pm 5.97)$ and mean schooling years of 3.33 ( \pm 2.84$)$. No statistically significant difference with the control-literate group was found on schooling years $(p=0.818)$ and gender distribution $(p=0.075)$, but the AD-literate group was older than the control group. $(p<0.001)$.

Considering the entire sample of $A D$ cases, the AUC-ROC was 0.980 (Cl 95\% 0.915-0.998) for the DRBCSB and 0.931 (Cl 95\% 0.846-0.977) for the DR-CER$A D$. Again, a trend for significance was observed $(p=$ 0.08 ). Within the illiterate population, a difference was found in accuracy between tests $(p=0.028)$, as the AUC-ROC for the DR-BCSB test was 0.998 (Cl 95\% 0.886-1.000) and for the DR-CERAD was 0.850 (0.6800.950). Among individuals with one or more years of schooling, no difference in accuracy for the diagnosis of $A D$ was found between tests $(p=0.369)$. The AUC-ROC for the DR-BCSB was 0.974 (Cl 95\% 0.864$0.996)$ and for the DR-CERAD was 0.994 (0.900-1.000).

\section{DISCUSSION}

Low educational status, while being associated with higher prevalence of dementia among different populations ${ }^{20,22,23}$, rep resents a challenge when evaluating individual with suspected dementia. Individuals with lower educational level may perform worse on certain neuropsychological tests, consequently creating an educational bias in the diagnostic approach of dementia. There is also a relative paucity of studies focusing specifically on neuropsychological tests for illiterates, and thus on the diagnosis of dementia in a group that composes a significant fraction of the elderly population in developing countries. There lies the need of adequate tools for the evaluation of populations with mixed educational background.

Both delayed recall tests showed high accuracy in the diagnosis of dementia or AD (as reported by previous studies $\left.{ }^{3,4,5,7}\right)$. However, when only illiterates were considered, the DR-BCSB showed higher accuracy than the DR-CERAD. Similar results were obtained when only $A D$ cases were analyzed. No diffe rence was found between these tests for the diagno- sis of dementia or $A D$ in the literate groups, while there was a trend for significance when the entire population was considered.

The disparity found among illiterates could be explained by the existence of two learning pathways (auditory and visual) in the delayed recall of simple objects presented as line drawings from the BCSB, as the individual sees and names the drawings, while the delayed recall of a word list test limits learning to the auditory pathway in illiterate individuals. On the other hand, literates may use both pathways for memory formation in both tests, which could explain the lack of diff e rence in accuracy between the tests. When analyzing the entire population, the results from the literate population had probably masked the difference found in the illiterate population.

The number of individuals in each group is relatively small in this study, and there were age differences between dementia and control groups, either among the illiterate or literate individuals, those with dementia being older. Although this age difference may have contributed to the higher accuracy of both delayed recall tests for the diagnosis of dementia, it $p$ robably did not interf e re in our findings of better accuracy of the delayed recall test from the BCSB because there were no age diff e rences either between illiterates and literates with dementia or between illiterates and literates of the control groups. Although there were more women in the illiterate group, a previous study did not show gender influence on the performance in these delayed recall tests ${ }^{6}$.

Summing up, applying the DR-BCSB in preference to the DR-CERAD in the diagnostic approach of dementia or $A D$ (as similar results were found when just the AD population was considered) may be justified when there is a high percentage of illiterates in the population. A more extensive study, including a higher number of individuals from different populations, is still necessary so that the results and conclusions presented here may be further substantiated.

\section{REFERENCES}

1. Welsh K, Butters N, Hughes J, Mohs R, Heyman A. Detection of abnormal memory decline in mild cases of Alzheimer's disease using CERAD neuropsychological measures. Arch Neurol 1991;48:278-281.

2. Morris JC, Heyman A, Mohs RC, et al., and the CERAD investigators. The Consortium to Establish a Registry for Alzheimer's Disease (CERAD): Part I. clinical and neuropsychological assessment of Alzheimer's disease. Neurology1989;39:1159-1165.

3. Chen P, Ratcliff G, Belle SH, Cauley JA, DeKosky ST, Ganguli M. Cognitive tests that best discriminate between presymptomatic AD and those who remain nondemented. Neurology 2000; 55:1847-1853.

4. Bertolucci PH, Okamoto IH, Brucki SM, Siviero MO, Toniolo J Neto, Ramos LR. Applicability of the CERAD neuropsychological battery to Brazilian elderly. Arq Neuropsiquiatr 2001;59:532-536. 
5. Prince M, Acosta D, Chiu H, Scafuza M, Va rghese M, for the 10/66 Dementia Research Group. Dementia diagnosis in developing countries: a cross-cultural validation study. Lancet 2003;361:909-917.

6. Nitrini R, Caramelli P, Herrera E Jr, et al. Performance of illiterate and literate nondemented elderly subjects in two tests of long-term memory. J Int Neuropsychol Soc 2004;10:634-638.

7. Nitrini R, Lefèvre BH, Mathias SC, et al. Testes neuropsicológicos de aplicação simples para o diagnóstico de demências. Arq Neuropsiquiatr 1994;52:457-465.

8. Nitrini R, Caramelli P, Herrera E Jr, et al. Incidence of dementia in a community-dwelling Brazilian population. Alzheimer Dis Assoc Disord 2004;18:241-246.

9. Pfeffer RI, Kurosaki TT, Harrah CH Jr, Chance JM, Filos S. Measurement of functional activities in older adults in the community. J Gerontol 1982;37:323-329.

10. Folstein MF, Folstein SE, McHugh PR. "Mini-mental State": a practical method for grading the cognitive state of patients for the clinician. J Psychiatr Res 1975;12:189-198.

11. Bertolucci PHF, Brucki SMD, Campacci SR, Juliano Y. O Mini-exame do Estado Mental em uma população geral: impacto da escolaridade. Arq Neuropsiquiatr 1994;52:1-7.

12. Sunderland T, Hill JL, Mellow AM, et al. Clock drawing in Alzheimer's disease: a novel measure of dementia severity. J Am Geriatr Soc 1989;37: 725-729.

13. ReisbergB, Borenstein J, Salob SP, Ferris SH, Franssen E, Georgotas A. Behavioral symptoms in Alzheimer's disease: phenomenology and treatment. J Clin Psychiatry 1987;48(Suppl):S9-S15.

14. Alexopoulos G, Abrams R, Young R, Shamoian C. Cornell scale for depression in dementia. Biol Psychiatry 1988;23:271-284.
15. Morris JC. The Clinical Dementia Rating (CDR): current version and scoring rules. Neurology 1993;43:2412-2414.

16. American Psychiatric Association. Diagnostic and statistical manual of mental disorders, ( $4^{\text {th }}$ ed.). Washington, DC: American Psychiatric Association Press, 1994.

17. McKhann G, Drachman D, Folstein MF, Katzman R, Price D, Stadlan EM. Clinical diagnosis of Alzheimer's disease: report of the NINCDS-ADRDA work group under the auspices of Department of Health and Human Services Task Force on Alzheimer's Disease. Neurology 1984;34: 939-944.

18. Román GC, Tatemichi TK, Erkinjuntti T, et al. Vascular dementia: diagnostic criteria for research studies: report of the NINDS-AIREN international workshop. Neurology 1993;43:250-260.

19. McKeith IG, Galasko D, Kosaka K, et al. Consensus guidelines for the clinical and pathologic diagnosis of dementia with Lewy bodies (DLB): report of the consortium on DLB international workshop. Neurology 1996;47:1113-1124.

20. Herrera E Jr, Caramelli P, Silveira ASB, Nitrini R. Epidemiologic survey of dementia in a community-dwelling Brazilian population. Alzheimer Dis Assoc Disord 2002;16:103-108.

21. Hanley JA, McNeil BJ. A method of comparing the areas under receiver operating characteristic curves derived from the same cases. Radiology 1983;48:839-843.

22. Zhang MY, Katzman R, Salmon D, et al. The prevalence of dementia and Alzheimer's disease in Shanghai, China: impact of age, gender and education. Ann Neurol 1990;27:428-437.

23. Callahan CM, Hall KS, Hui SL, Musick BS, Unverzagt FW, Hendrie HC. Relationship of age, education, and occupation with dementia among a community-based sample of African Americans. Arch Neurol 1996;53:134-140. 